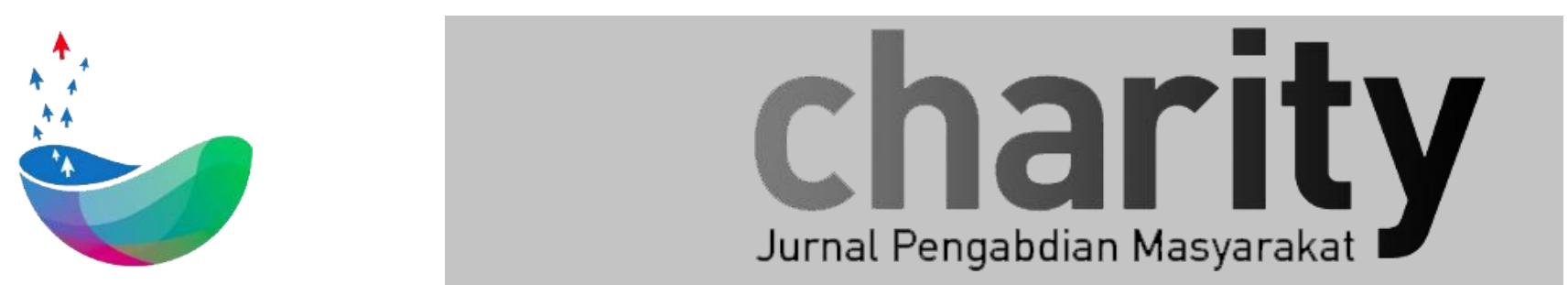

\title{
INSTALASI JARINGAN KOMPUTER DAN SERVER UNTUK MENYELENGGARAKAN SIMULASI DAN PELAKSANAAN UNBK BAGI SISWA KELAS XII T.A. 2018/2019 MA SALAFIYAH AL FALAH BANDUNG
}

Ratri Dwi Atmaja, Ledya Novamizanti dan Heriyono Lalu

Universitas Telkom

\section{INFO ARTIKEL}

Diterima 5 April 2019

Direvisi 12 April 2019

Disetujui 30 Agustus 2019

Tersedia Online 6 Juli 2020

$\begin{array}{ll}\text { Keyword: } & \begin{array}{l}\text { Profil Produk, Profil } \\ \text { Anggota, Promosi, } \\ \text { Keanggotan }\end{array}\end{array}$

\begin{abstract}
ABSTRAK
MA Salafiyah Al Falah merupakan sekolah yang berlokasi di Jalan Ciganitri Pertanian, Desa Lengkong, Kecamatan Bojongsoang, Kabupaten Bandung. Pada tahun 2019 MA Salafiyah terdaftar sebagai salah satu sekolah yang mengikuti Ujian Nasional Berbasis Komputer (UNBK). Untuk dapat mengikuti UNBK, sekolah diwajibkan memiliki infrastruktur yang memadai untuk menjamin suksesnya kegiatan pelaksanaan UNBK. Karena MA Salafiyah belum memiliki infrastruktur yang cukup maka kami membantu kegiatan tersebut sebagai bentuk pengabdian kepada masyarakat. Bentuk kegiatan berupa pelaksanaan Simulasi II UAMBN-BK, gladi bersih UAMBN-BK, gladi bersih UNBK, UAMBN-BK, dan UNBK. Kegiatan tersebut dilaksanakan di Laboratorium Pengolahan Sinyal Digital, Fakultas Teknik Elektro, Universitas Telkom. Peserta berjumlah 16 siswa kelas XII tahun ajaran 2018/2019. Untuk menyelenggarakan kegiatan tersebut, dibutuhkan 17 komputer (16 client dan 1 server) serta akses internet. Server berupa komputer dengan spesifikasi processor core i7, RAM 8 GB, dan HD 1 TB. Sesuai requirement pelaksanaan UNBK, yang disediakan akses internet hanyalah komputer server. Komputer server digunakan untuk mendownload soal ujian nasional dari server pusat Kementerian Agama dan mengupload hasil jawaban seluruh client (siswa) ke server pusat. Sedangkan antara komputer server dan komputer client menggunakan jaringan lokal.
\end{abstract}




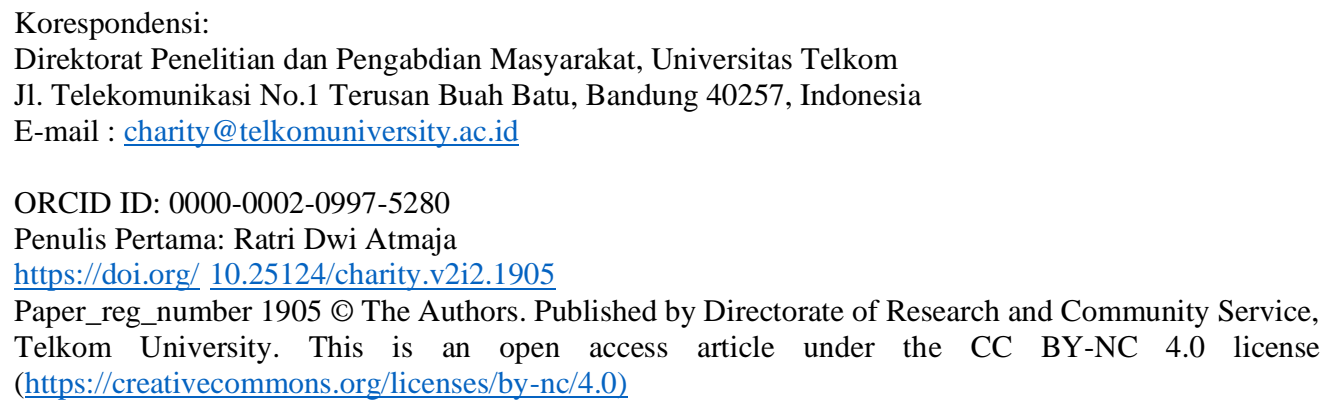

\section{LATAR BELAKANG}

MA Salafiyah dibawah Yayasan Al Falah merupakan sekolah yang berlokasi di Jalan Ciganitri Pertanian, Desa Lengkong, Kecamatan Bojongsoang, Kabupaten Bandung. MA Salafiyah hanya berjarak sekitar 3 kilometer atau 10 menit dari Universitas Telkom. Sejak tahun 2018 sekitar 10\% Madrasah Aliyah sekabupaten Bandung mengikuti ujian nasional dengan cara berbasis kertas (UNKP) karena sekolah memiliki siswa kelas XII yang jumlahnya banyak dan komputer yang jumlahnya terbatas sehingga tidak mungkin dilaksanakan UNBK dalam sehari maksimal 3 shift untuk mata pelajaran yang sama. Sedangkan sekitar 90\% lainnya sudah mulai diwajibkan mengikuti ujian nasional dengan cara berbasis komputer, termasuk MA Salafiyah Al Falah. Namun MA Salafiyah Al Falah belum memiliki infrastruktur yang memadai, sehingga diperlukan suatu bentuk kegiatan untuk membantu pelaksanaan UNBK tersebut.

\section{SOLUSI DAN LUARAN}

Dimulai dari Februari sampai April 2019 terdapat serangkaian kegiatan yang harus diikuti oleh MA Salafiyah Al Falah yaitu Simulasi II UAMBN-BK, gladi bersih UAMBN-BK, gladi bersih UNBK, UAMBN-BK, dan UNBK. Solusi yang ingin dicapai yaitu tersedianya infrastruktur berupa sejumlah komputer client dan server, jaringan komputer, serta akses internet untuk mendukung pelaksanaan serangkaian kegiatan tersebut. Sedangkan luaran yang ingin dicapai yaitu berupa jasa dalam bentuk kegiatan penyelenggaraan serangkaian kegiatan tersebut bagi siswa kelas XII tahun ajaran 2018/2019 MA Salafiyah Al Falah Bandung

\section{METODE PELAKSANAAN}

Bentuk kegiatan berupa pelaksanaan Simulasi II UAMBN-BK, gladi bersih UAMBN-BK, gladi bersih UNBK, UAMBN-BK, dan UNBK. Seluruh kegiatan tersebut dilaksanakan di Laboratorium Pengolahan Sinyal Digital, Fakultas Teknik Elektro, Universitas Telkom.

Tanggal dan waktu pelaksanaan Simulasi II UAMBN-BK sebagai berikut:

$$
\begin{aligned}
& \text { Hari/Tanggal }: \text { Senin s/d Rabu, } 18 \text { - } 20 \text { Februari } 2019 \\
& \text { Waktu } 08.00 \text { - } 10.00 \text { WIB } \\
& \text { Mata Pelajaran: Al-Quran Hadist, Fiqih, Sejarah Kebudayaan Islam }
\end{aligned}
$$

Tanggal dan waktu pelaksanaan Gladi Bersih UAMBN-BK sebagai berikut: 
Hari/Tanggal : Senin s/d Selasa, 25 - 26 Februari 2019

Waktu $\quad$ : $08.00-10.00 \mathrm{WIB}$

Mata Pelajaran: Al-Quran Hadist \& Fiqih, Sejarah Kebudayaan Islam

Tanggal dan waktu pelaksanaan Gladi Bersih UNBK sebagai berikut:

Hari/Tanggal : Senin s/d Selasa, 11 - 12 Maret 2019

Waktu $\quad$ : $08.00-10.00$ WIB

Mata Pelajaran: Bahasa Inggris, Matematika

Tanggal dan waktu pelaksanaan UAMBN-BK sebagai berikut:

Hari/Tanggal : Rabu s/d Jumat, 13 - 15 Maret 2019

Waktu : $08.00-10.00 \mathrm{WIB}$

Mata Pelajaran: Al-Quran Hadist, Fiqih, Sejarah Kebudayaan Islam

Tanggal dan waktu pelaksanaan UNBK sebagai berikut:

Hari/Tanggal : Senin s/d Selasa, Kamis dan Senin, 1, 2, 4 dan 8 April 2019

Waktu $\quad$ : $08.00-10.00 \mathrm{WIB}$

Mata Pelajaran: Bahasa Indonesia, Matematika, Bahasa Inggris, Sosiologi

Peserta berjumlah 16 siswa kelas XII tahun ajaran 2018/2019. Untuk menyelenggarakan kegiatan tersebut, dibutuhkan 17 komputer (16 client dan 1 server) serta akses internet. Server berupa komputer dengan spesifikasi minimal yaitu processor core i7, RAM 8 GB, dan HD 1 TB. Topologi jaringan komputer yang digunakan mengikuti gambar berikut:

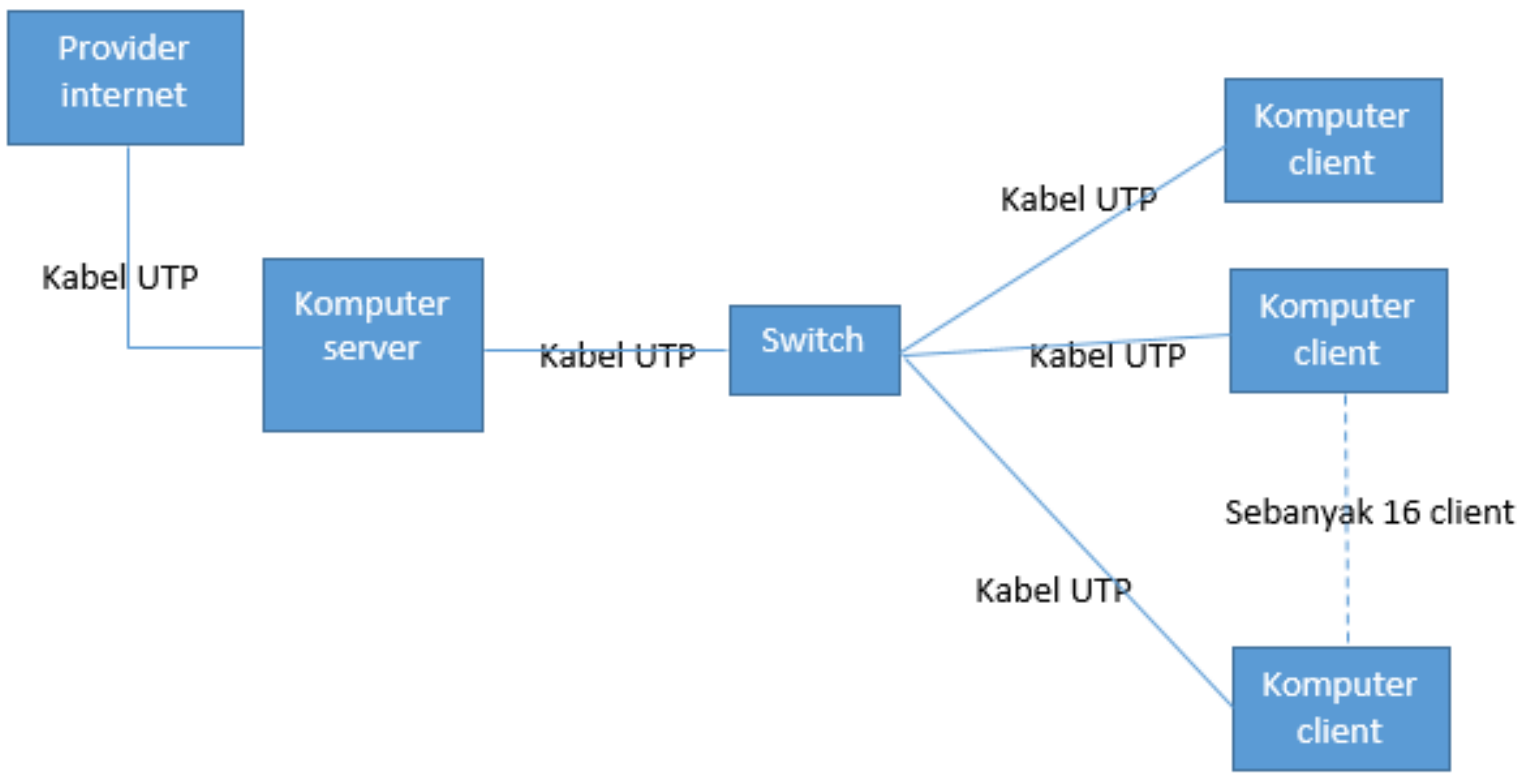

Gambar 1. Topologi jaringan komputer yang digunakan 
Sesuai requirement pelaksanaan UNBK, pada gambar diatas yang disediakan akses internet hanyalah komputer server. Komputer server digunakan untuk mendownload soal ujian nasional dari server pusat Kementerian Agama dan mengupload hasil jawaban seluruh client (siswa) ke server pusat. Sedangkan antara komputer server dan komputer client menggunakan jaringan lokal. Sebelum hari pelaksanaan, komputer server dilakukan sinkronisasi dengan server pusat terlebih dahulu agar pada saat hari pelaksanaan computer server dapat mendownload soal ujian nasional dari server pusat maupun mengupload hasil jawaban seluruh client (siswa) ke server pusat.

\section{KESIMPULAN}

Pelaksanaan Simulasi II UAMBN-BK, gladi bersih UAMBN-BK, gladi bersih UNBK, UAMBN-BK, dan UNBK bagi siswa kelas XII tahun ajaran 2018/2019 MA Salafiyah Al Falah Bandung berjalan dengan baik. Untuk melaksanakan serangkaian kegiatan tersebut diperlukan infrastruktur berupa:

- 16 komputer client

- 1 komputer server dengan spesifikasi minimal processor core i7, RAM 8 GB, dan HD 1 TB.

- Akses internet untuk komputer server

- Kabel UTP/kabel LAN beserta konektor RJ45

- 1 UPS untuk komputer server

- 1 switch 24 port

- 16 headset untuk ujian listening bahasa inggris

- Ruangan, kursi, meja, dan sumber listrik AC

- LAN card untuk komputer server

\section{DOKUMENTASI KEGIATAN}
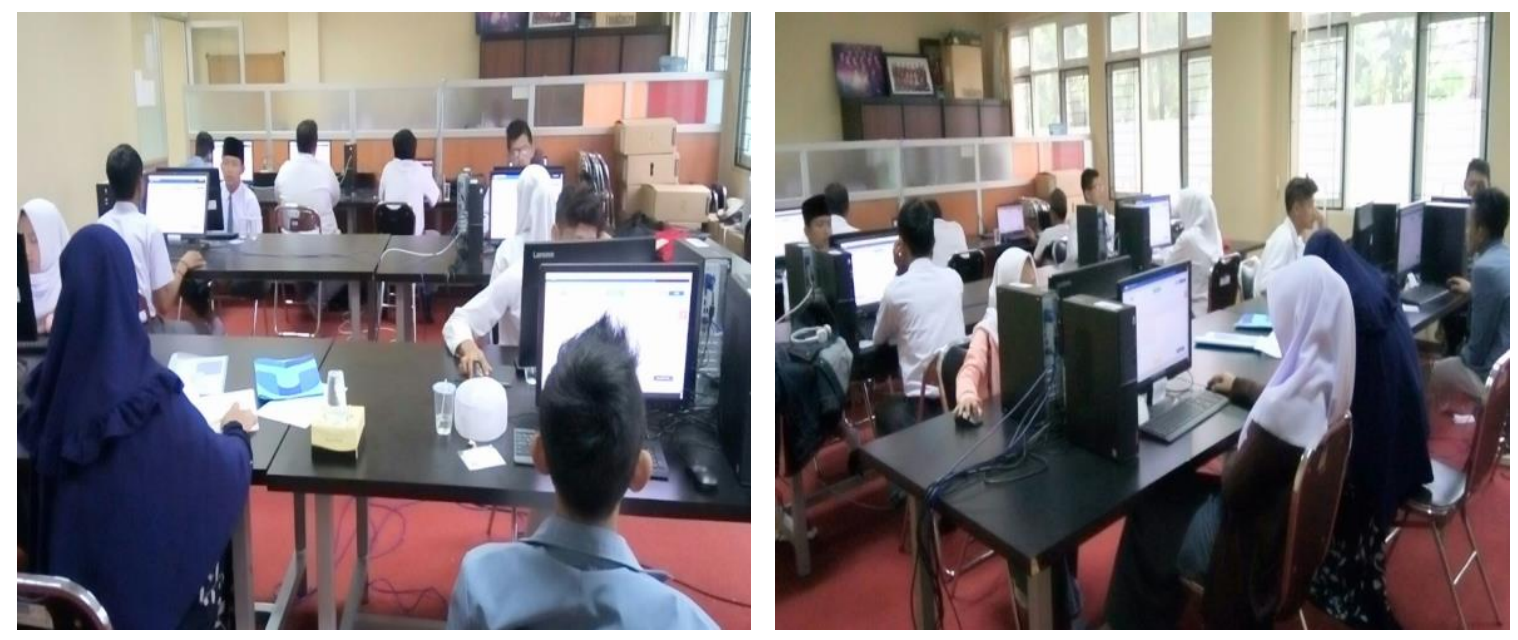

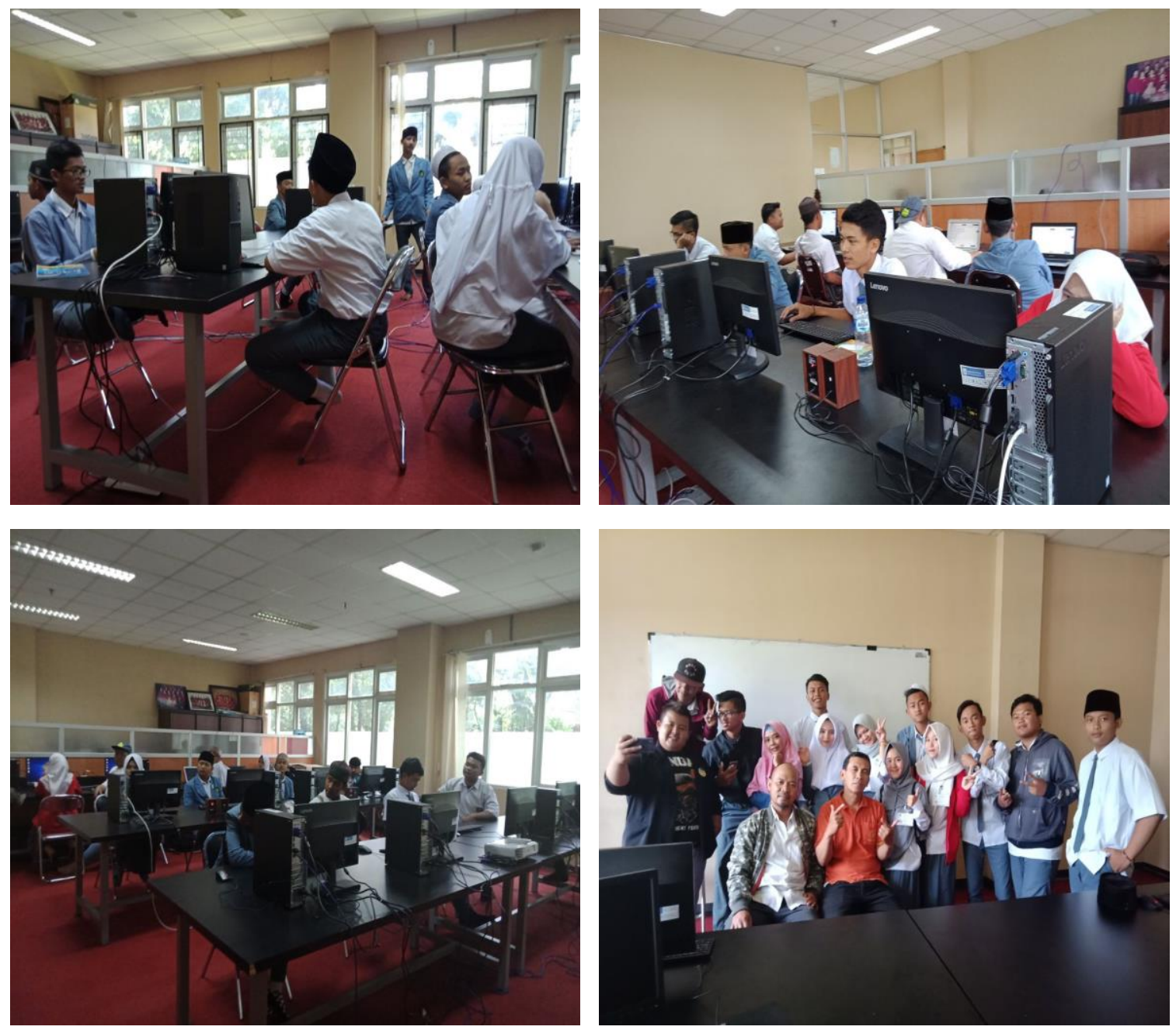